\title{
Erratum: Identifying factors associated
with the discharge of male State patients \\ Erratum: Identifying factors associated
with the discharge of male State patients from Weskoppies Hospital
}

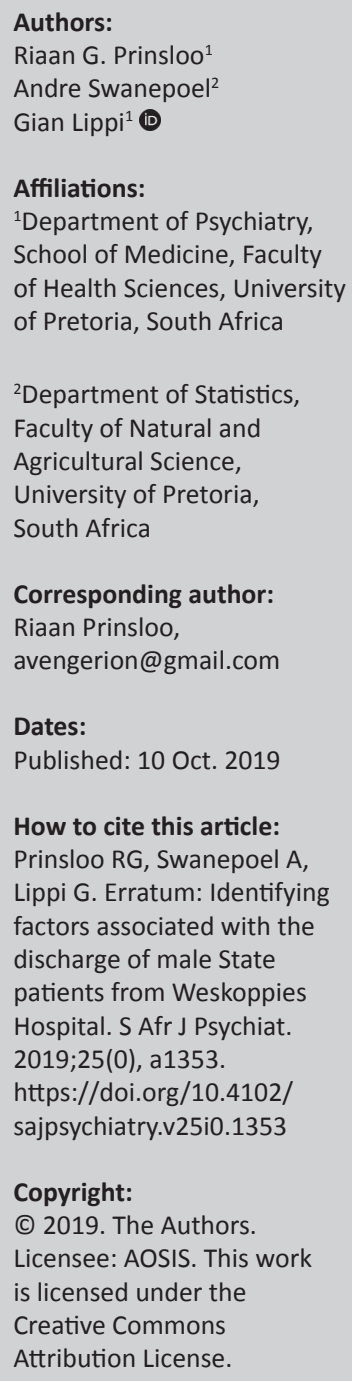

Copyright:

(C) 2019. The Authors. Licensee: AOSIS. This work

is licensed under the

Creative Commons

Attribution License.

In the author list of this article published earlier, Gian Lippi's ORCID was unintentionally misprinted as http:/ / orcid.org/0000-0002-9545-240X.

The correct ORCID for Gian Lippi is http://orcid.org/0000-0002-1214-3573. The publisher sincerely regrets this error and apologises for any inconvenience caused. 